\title{
154 NUTRITION AND SPORTS PERFORMANCE
}

S Manikandan, D Selvam Department of Physical Education and Sports Sciences, Annamalai University, Chidambaram, Tamil Nadu, India

\subsection{6/bjsm.2010.078725.154}

The awareness of nutrition playing an important role in sports performance. Many factors can impact the performance of a sports person during competition which may be related to different domains. The most commonly encountered nutritional related problem among sports person is their failure to consume sufficient total of food energy. Food is composed of six basic substance: carbohydrates, proteins, fats, vitamins, minerals and water. Each one of these has specific function in providing nourishment for the body. For the sportsman, it is of critical importance to recognise what each does to his body under the physical, mental and emotional strains of competition. The duration and the intensity of the exercise involved in a given sports will determine the principal source of energy used in meeting the work demands of that particular sports. The certain nutrition and dietary approaches an enhance the sports performance and also nutrition is essential for an athletes good performance. The athlete's diet should be high in carbohydrates, moderate in proteins and low in fat. 